\title{
PETRÓLEO DE MARRAKESH E SENHORAS DA SOLIDÃO: UM DEBATE SOBRE PROSTITUIÇÃO A PARTIR DA ANÁLISE DO LONGA METRAGEM MARROQUINO: "MUITO AMADAS".
}

\section{MARRAKESH OIL AND LADIES OF SOLITUDE: A DEBATE ABOUT PROSTITUTION THROUGH THE ANALYSIS OF THE MOROCCAN MOVIE “MUCH LOVED”}

Flávia X. M. Paniz ${ }^{1}$

\author{
MUCH LOVED \\ Drama (França e Marrocos) \\ 108 minutos, 2015. Celluloid Dreams \\ Direção e roteiro: Nabil Ayouch \\ Produção: Nabil Ayouch, Saïd Hamich, Eric Poulet e Sanaa Boutayeb \\ Música: Mike Kourtzer
}

\begin{abstract}
Resumo: 0 artigo busca apresentar uma resenha crítica do filme "Muito Amadas" (Much Loved) escrito e dirigido pelo cineasta franco-marroquino Nabil Ayouch e exibido no festival de Cannes no ano de 2015. O longa metragem em questão narra a história de quatro mulheres marroquinas que trabalham como prostitutas na cidade de Marrakesh. 0 texto apresenta uma discussão sobre os dilemas que envolvem os debates acadêmicos contemporâneos sobre prostituição buscando relacionar como a construção das personagens no roteiro se encaixam e também transbordam algumas das perspectivas políticas e analíticas sobre trabalho sexual discutidas nas ciências sociais hoje.
\end{abstract}

Palavras-chave: Marrocos - Gênero - Prostituição.
Abstract: The article critically reviews the movie "Much Loved", written and directed by the FrenchMoroccan filmmaker Nabil Youch and displayed at the 2015 Cannes Movie Festival. The film tells the story of four Moroccan women who work as prostitutes in the city of Marrakesh. This article discusses the dilemmas in contemporary academic debates about prostitution, aiming to show how the construction of the characters on the screenplay fits and also transcends some of the analytical and political perspectives on sex work discussed at social sciences today.

Keywords: Morocco - Gender - Prostitution.

\section{Apresentação}

Banido no Marrocos e exibido pela primeira vez no festival de Cannes em maio de 2015, o longa metragem Much loved escrito e dirigido pelo cineasta franco-marroquino Nabil Ayouch narra a trajetória de quatro mulheres jovens, solteiras e prostitutas da cidade de Marrakesh². Mais do que um retrato do cenário contemporâneo da prostituição

\footnotetext{
${ }^{1}$ Flávia X. M. Paniz é doutoranda do Programa de Pós-Graduação em Sociologia da Universidade Estadual de Campinas (UNICAMP) e realiza pesquisa sobre questões de gênero e feminismo pós-colonial no contexto contemporâneo da Questão Curda. Link para o Currículo Lattes: http://lattes.cnpq.br/7844471132977594. Contato: flaviapaniz@gmail.com.

${ }^{2}$ O filme foi exibido também nos festivais de Munique, Angoulême, Gindou, Toronto, Helsinki, Varsóvia, Londres, Estolcolmo, Diverciné no Canadá; e nos circuitos independentes, Brasil, Portugal, Alemanha e Estados Unidos.
} 
no Marrocos, as vidas de Noha, Randa, Soukaina e Hlima simbolizam o paradoxo moral e jurídico o qual se insere o próprio debate sobre prostituição no país. Distante de uma perspectiva salvacionista e igualmente distante da romantização do trabalho do sexual, a narrativa cinematográfica apresentada por Ayouch se destaca sobretudo pela quebra de expectativa marcada pela ausência de estereótipos convencionais no tratamento dado ao tema da prostituição no Marrocos.

O espaço da cidade, os figurinos, a alvorada, as entregas de dinheiro à família, o silêncio, o véu e as próprias corporalidades, por vezes comedidas, das personagens no encontro com seus parentes durante o dia se contrastam com as festas, os encontros com os clientes, danças, dinheiro, propina, álcool, e a tênue linha entre consentimento e violência sexual representadas simbolicamente pelas imagens da vida noturna. Na fissura entre estes dois espaços reside a própria condenação jurídica e moral da prostituição, que reconfigura suas relações afetivas, sociais, a maternidade e a própria ideia de família. Assim, no apartamento compartilhado, elas constituem seu próprio núcleo familiar e transitam conjuntamente entre estes dois mundos.

\section{Mulheres, marroquinas, árabes, muçulmanas e prostitutas? Agência e liberdade.}

De acordo com Fatima Sadiqi (2008), no artigo "Estereótipos e mulheres na cultura marroquina”, o processo de nomeação e caracterização dos estereótipos é o primeiro passo para desmistificar a pressuposição de homogeneidade presente no imaginário sobre mulheres marroquinas. Segundo a autora, a diversidade presente na multiplicidade de respostas aos diversos estereótipos, que reforçam ideias de passividade e submissão, coloca em evidencia a autonomia das mulheres marroquinas para elaborar formas de resistência através das próprias narrativas.

Reformulado em 2004, o Moudawana, conhecido como Código da Família e responsável por regular os direitos das mulheres e crianças no Marrocos, representou, em muitos aspectos, conquistas em direção à igualdade de gênero e foi celebrado como um grande passo inicial para a acolhida das demandas das mulheres no país (Afilal, 2008). Segundo Rachida Afilial, que analisa mudanças do código da família entre 1958 e 2004:

Contextualizado por uma abordagem "jurídica", três grandes princípios constituem sua estrutura: garantir os direitos das mulheres, preservar os direitos e a dignidade do homem e fazer prevalecer o interesse supremo da criança. A abordagem "família" sobre o eixo da solidariedade, a complementaridade e a busca da coesão é amplamente privilegiada" (Afilal, 2008: 123).

Dentre as modificações realizadas, o direito ao divórcio por parte das mulheres e questões relativas ao cuidado e a guarda de filhos são as mais significativas do ponto de vista do debate público. No geral diferentes perspectivas analíticas e políticas emergem nos debates sobre as mudanças do Moudawana, principalmente entre dois grupos: os de mulheres marroquinas que se consideram feministas com raízes árabe-muçulmanas e eventualmente críticas do chamado feminismo europeu; e os grupos de movimentos 


\section{resenha de filme}

islâmicos que exigem direitos para as mulheres no interior dos processos de islamização da sociedade e do Estado. (Ramírez, 2006). Uma das questões ainda presentes no atual no código da família é a proibição da relação sexual fora do casamento. Isso significa que outras configurações de exercício da vida sexual fora do espaço conjugal, sobretudo a prostituição, são consideradas ilegais ${ }^{3}$. Visto dessa maneira, a própria existência das narrativas de Noha, Randa, Soukaina e Hlima rompem com estereótipos, sobretudo Hlima, que se prostitui estando grávida. Isto porque, apesar da violência, o caráter da autonomia é representado e reforçado através da maneira como controlam o próprio corpo, o trabalho, suas próprias vidas, projetando uma identidade não estigmatizada, que está além das dinâmicas sociais estabelecidas. 0 poder de controle sobre suas próprias narrativas é simbolizado na última cena do filme quando elas fogem de Marrakesh para Agadir. A representação da liberdade se concretiza efetivamente através da composição da paisagem que marca o encontro das personagens com a praia e o mar que as separa do continente europeu.

$$
\begin{array}{r}
\text { - Vejo um avião. } \\
\text { - Um avião? }
\end{array}
$$

- Um avião com nós três dentro. Estamos rindo, felizes.

- Aonde vai esse avião?

-Para uma ilha distante, onde seremos lindas sem ter que usar maquiagem, nem roupas chiques. Lá seremos respeitadas e todos os homens nos tratarão como damas. $^{4}$

\section{Autonomia e vitimização: perspectivas sobre as condições da prostituição.}

A obra cinematográfica de Ayouch teve sua exibição banida no Marrocos acusada, entre outras coisas, de difamação da sociedade marroquina ${ }^{5}$. No geral a recepção do filme no país foi bastante negativa. Houve ameaças de violência contra o diretor e uma das atrizes principais, e ambos se radicaram na França posteriormente. Considerada controversa, a construção das personagens no contexto da prostituição apresenta o rompimento de quatro marcadores sociais que historicamente estabelecem uma relação de vitimização com a narrativa de prostitutas. No caso, mulheres, muçulmanas, marroquinas e prostitutas poderiam ser usualmente compreendidas como vítimas das desigualdades de gênero e do sexismo, das imposições religiosas, do sistema econômico capitalista, da colonização e da marginalização social que configurariam estruturas de poder que sustentam argumentos de que elas seriam obrigadas a venderem seus próprios corpos e seriam, portanto, desprovidas de autonomia, sem a capacidade de escolha. (Ramíres, 2014: 53); (Lughod, 2013).

\footnotetext{
${ }^{3}$ Para conhecer mais sobre as implicações práticas do Moudawana na vida das mulheres marroquinas, a antropóloga Rebeca Slenes realizou trabalho de campo em duas ONG's de apoio a mulheres marroquinas e apresenta os contrapontos destes debates em sua dissertação de mestrado. (Slenes, 2014)

${ }^{4}$ Diálogo final da última cena do filme.

${ }^{5}$ Cf. O artigo de Ainda Alami no jornal The New York Times: https://www.nytimes.com/2015/06/04/ arts/international/moroccan-film-about-prostitution-creates-uproar.html acessado em 30/06/2017. A crítica do jornal The Guardian https://www.theguardian.com/film/2015/nov/10/much-loved-reviewsex-trade-morocco-nabil-ayouch-loubna-abidar. Acessado em 30/06/2017. E BBC http://www.bbc.com/ news/blogs-trending-33010995. Acessado em 30/06/2017.
} 
Uma das representações mais expressivas sobre os sentidos das relações de poder (des)construídas no filme é a mediação financeira. 0 pagamento de propina para que os seguranças das festas e das boates as deixem trabalhar, o pagamento do salário de Said, (o motorista que atua como uma espécie de segurança particular), o pagamento dos sustentos de seus parentes e filhos, e até mesmo de um namorado, simbolizam a capacidade de construção da autonomia financeira que expressa a liberdade de gestão de suas próprias vidas, elas são "o petróleo de Marrakesh", como diz um dos clientes; e ao mesmo tempo isto não é suficiente para que sejam acolhidas em outros espaços, são passíveis de serem violentadas e humilhadas, ("sou a senhora de todos eles, senhora da solidão", como aparece na fala final de uma das personagens), o que nos leva a buscar a compreensão do caráter moral pelo qual se insere o debate sobre prostituição.

Diana Triviño (2014) apresenta uma trajetória das diferentes concepções de prostituição em diferentes países do continente africano ao longo dos anos 1980, 1990 e 2000: A palavra prostituição não faz referência somente à troca de sexo por dinheiro ou bens, mas, sobretudo, a um tipo de conduta humana que devido a suas práticas sexuais é definida e estigmatizada como um desvio social. Esta compreensão da prostituição surge através de processos históricos específicos no mundo Ocidental, principalmente na construção dialética de uma sexualidade "legítima" e "ilegítima". Nesta, o matrimônio e posteriormente as relações de relacionamento são convertidas nas únicas situações nas quais a sexualidade é permitida. A validade desta compreensão da prostituição se estende até hoje e, apesar de sua gestação no Ocidente, tem marcado as interpretações sobre a prostituição em contextos não- Ocidentais (TRIVIÑO, 2014:53, tradução minha).

De acordo com o artigo de Diana Triviño (2014) há uma historicidade na concepção de prostituição em países africanos que vem sendo pesquisada e discutida nos últimos quarenta anos. Em linhas gerais, os debates sobre o controle e a proibição da prostituição possuem três narrativas consolidadas: a primeira delas, constituída na década de 1980, tangencia os debates sobre saúde pública e higiene, alocando a questão da prostituição para o um lugar de potencial foco de contaminação de doenças sexualmente transmissíveis, como os casos do HIV e Sífilis. Assim, o argumento da necessidade de frear essa prática ganha força com a projeção de combate a epidemias globais. Posteriormente, sobretudo no início dos anos 1990, diversos movimentos que apoiavam a criminalização da prostituição em caráter global se apropriaram da retórica que hoje é conhecida como salvacionista, que se assenta na perspectiva de que a prostituição é uma forma contemporânea de escravidão das mulheres, sobretudo em contextos de pobreza e miséria. Esta retórica, caracterizada pela clivagem socioeconômica da argumentação, ganha força a partir da elaboração do paralelo com a colonização, que estabelece uma relação de troca entre bens materiais e exploração sexual de mulheres, e posiciona o debate sobre prostituição como um efeito ou consequência do subdesenvolvimento, alocando-as como vítimas das condições econômicas e da desigualdade social em escala global.

Ainda segundo o argumento da autora é a partir dos anos 1990 que os contextos culturais passaram a tornarem-se relevantes nos debates sobre prostituição, e até mesmo a própria palavra "prostituição" passa a ser contestada por não oferecer explicações suficientes 
sobre as potencialidades das relações de troca entre sexo e dinheiro. Deste debate emergem, nos anos 2000 principalmente, duas categorias: sexo para sobreviver e sexo transacional: a primeira diz respeito à predominância do caráter econômico como justificativa para a prostituição, que inclui também a relação do sexo com a troca de alimentos, água e bens essenciais à manutenção da vida; e a segunda diz respeito às mulheres que possuem meios econômicos de subsistência e ainda assim desejam ascender socialmente, pertencer a uma nova classe social através do consumo, e encontram na prostituição uma maneira de fazêlo. Complementando esta análise, de acordo com a antropóloga Adriana Piscitelli (2016), o combate ao tráfico internacional de pessoas e os debates sobre experiências de violência e eventuais traumas psicológicos também reverberam nos debates contemporâneos sobre o controle e a proibição do trabalho sexual.

Dentre as possibilidades explicitadas acima, a única que toma a autonomia das mulheres prostitutas como sujeitos não-subordinados e conscientes em suas próprias escolhas e narrativas é a de sexo transacional, porque desloca o caráter exclusivamente econômico da centralidade da pauta e coloca outros fatores em perspectiva. E, ao mesmo tempo, estes argumentos, a constituição das masculinidades, do desejo e do turismo sexual emergem como fator explicativo da manutenção da própria prostituição.

No contexto marroquino, apesar da proibição da prostituição, em Muito Amadas sua manutenção ocorre abertamente e em múltiplas instâncias, simbolizada através dos papeis desempenhados pelas instituições públicas, que são representadas pela permissividade dos policiais e seguranças dos clubes noturnos e também através da representação dos clientes, que são empresários do ramo do Petróleo, sheiks e demais personalidades, principalmente da Arábia Saudita, e demais países do Oriente Médio, África e Europa, e que configuram um mercado internacional de turismo sexual no filme.

\section{Abolicionismo, regulamentação ou proibicionismo: as novas configurações do debate sobre prostituição}

Uma interessante contribuição para a reflexão sobre prostituição é justamente pensar no paradoxo sobre o qual está inserido o debate: por um lado, em diversos países, incluindo o Marrocos, a prostituição é juridicamente proibida e por vezes considerada um crime, e por outro lado é publicamente reconhecida e reforçada de maneira informal em múltiplas instâncias. No filme, a representação das instituições do Estado se configura a partir da metáfora inscrita nos papeis atribuídos aos policiais, que tentam roubar uma adolescente grávida, desvelam um soco em sua barriga, cobram propina, negligenciam uma tentativa de homicídio sofrida por uma das prostitutas e estupram outra. Desta maneira, se estabelece uma relação contraditória e paradoxal entre a proibição da prostituição e o exercício de poder do Estado sobre os corpos das mulheres através do exercício de uma dupla moral, e afasta o debate da atribuição da condição socioeconômica como justificativa única. Este debate deixa em aberto a questão: Como é possível estabelecer os 


\title{
resenha de filme
}

parâmetros para reflexões que determinam a tênue linha entre autonomia e exploração física e estrutural no contexto do trabalho sexual?

De acordo com a antropóloga Adriana Piscitelli (2012), que realiza pesquisa sobre mercado do sexo através dos estudos de gênero, os debates sobre prostituição são bastante heterogêneos, e atualmente no Brasil são constituídos a partir de três vertentes: o abolicionismo que, dentre as diferentes perspectivas, "considera a prostituição como violência sexista, que foram parte de um continuum que se inicia na publicidade, inclui espetáculos, o mercado matrimonial, a pornografia e culmina na prostituição" (PISCITELLI, 2012: 21), articulando, portanto, uma relação entre prostituição e escravidão. 0 proibicionismo, que em linhas gerais articula as relações estruturais de poder em torno da prostituição e busca coibi-la sem criminalizar as mulheres, consideradas vítimas, e atuam na criminalização do entorno de suas relações, como a exploração, a violência de gênero, o tráfico sexual, o turismo sexual entre outros. E a vertente que defende a regulamentação, que opera na chave da compreensão de que apesar dos esforços para a proibição e coibição da prostituição através de políticas públicas que ofereçam condições de autonomia e escolhas às mulheres, não há indícios de mudanças significativas neste campo. Este é o argumento que corrobora a defesa da regulamentação como uma saída capaz oferecer condições de segurança, saúde e trabalho suficientes para que a atividade sexual possa ser exercida com autonomia e com garantia de direitos civis e trabalhistas. Segundo a autora:

\begin{abstract}
Nessas leituras, que consideram que há uma imensa dificuldade no feminismo em avançar nesse debate, também se incluem perspectivas que situam a prostituição no âmbito do direito de escolha das mulheres e rejeitam a ideia de que a prostituta esteja mercantilizando o corpo e as demais mulheres não: a diferença estaria no moralismo com que é percebida qualquer atividade sexual. (PISCITELLI, 2012:22)
\end{abstract}

\section{Masculinidades, feminilidades identidades e sexualidade: 0 caso do sheik gay, a prostituta lésbica e a colega transexual.}

Retomando a questão do paradoxo moral sobre o qual versa a própria narrativa do filme. Um dos diálogos que se destacam no roteiro é a caracterização das preferências por clientes. Alocadas para receber clientes internacionais em viagens de negócios no Marrocos, as personagens e demais colegas conversam em tom de deboche sobre suas preferências:

\footnotetext{
- Ela não sai com árabes, só com europeus. - Ela adora os europeus. Ela adora a AIDS, os porcos, os pão-duro. Eles não pagam, aqueles ratos. Compram frutas por unidade. Meia banana, meia maçã ... deveríamos ensiná-los a ser generosos. - Imploro a Deus por um saudita, belo, homem educado, de pinto pequeno e com muito dinheiro para que eu tenha uma bela noite.
}

Em outro momento afirmam temer clientes negros em razão dos tamanhos dos pênis que, em outra ocasião, teria lastimado o órgão genital de uma colega. As distinções 


\section{resenha de filme}

entre clientes não acontecem somente de acordo com a etnia ou nacionalidade, há uma preferência por empresariados do petróleo advindos da Arábia Saudita, que nas imagens do filme aparecem frequentemente esbanjando dinheiro e se autoproclamando "chefes do mundo"; e, por outro lado, elas não se relacionam com os traficantes de cocaína quenianos, do Vale do Rifte. No mesmo contexto, uma das personagens é verbalmente agredida por um cliente por se recusar a dançar e a fazer sexo com ele. As colegas a defendem e posteriormente descobrem que a colega era lésbica. Embora não houvesse nenhum tipo de expressão de moralidade com relação ao fato de uma das personagens ser lésbica, quando Soukaina se envolve com um cliente que prefere recitar uma poesia a fazer sexo, ela expressa um incômodo, enquanto o homem profere:

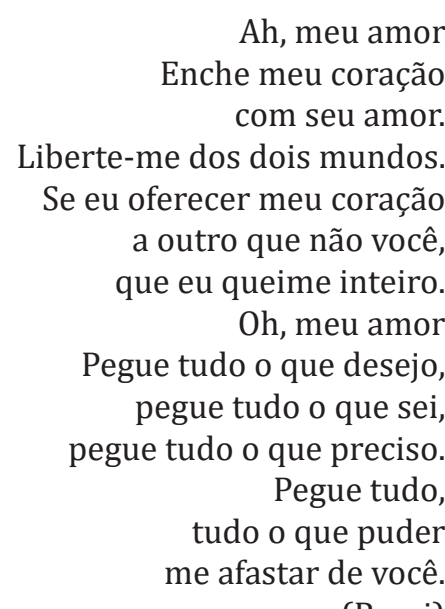

(Rumi)

A poesia não reconhecida por Soukaina é, na verdade, um conhecido poema persa de 1273, escrito por Mawlānā Jalāl-ad-Dīn Muhammad Rūmī ou simplesmente Rumi. 0 caráter sagrado de inspiração sufi do poema, quando inserido no contexto de uma festa com prostitutas contratadas, nos leva a compreender que a referência a dois mundos toma outro sentido. Quando Soukaina percebe que o cliente é homossexual, ela o xinga por haver rompido com sua honra de prostituta. Ele se sente ofendido e, por sua vez, a agride de forma violenta. Na tentativa de obter ajuda para realizar a denúncia pela violência, as personagens encontram uma conhecida travesti que se prostitui em uma rua. É a única cena em que mostra a prostituição no contexto de rua, de forma aberta. Na discussão causada por um desentendimento na rua, as personagens fogem no carro de Said, o motorista que atua como uma espécie de protetor, sempre em silêncio e de curiosa calma diante das situações.

Nas idas e vindas noturnas, o cenário da prostituição é ampliado para além do contexto das festas de alta classe frequentadas pelas protagonistas do filme. Em um hospital elas conhecem uma jovem grávida que, abandonada por seu antigo companheiro, havia fugido do interior para esconder a gravidez, dormia na rua e se prostituía. Um de seus clientes havia pago um programa com o equivalente a 34 reais e $10 \mathrm{~kg}$ de verdura. Depois, em um restaurante, se deparam com uma criança, um menino de aproximadamente oito anos de idade, que havia sido violentado e pedia comida. Os problemas com a polícia local 


\section{resenha de filme}

se agravam, elas haviam sido formalmente denunciadas e como já haviam sido violentadas por um dos policiais, resolvem partir. Alugam um carro de luxo, fazem reserva um hotel também luxuoso no litoral, e vão embora da cidade de Marrakesh.

O filme de Ayouch nos permite refletir sobre inúmeras questões no debate sobre prostituição. Uma delas, e talvez a principal causa da sensação paradoxal de estranhamento que imprime controvérsia ao filme, é justamente o retrato de mulheres, prostitutas, violentadas e marginalizadas que termina com risos e projeções de expectativas num final de tarde na praia. Não se trata de tentar compreender por que razões elas se prostituem ou não, mas de pensar como a narrativa escrita por Ayouch rompe clichês, demonstrando que há uma tênue linha que separa a prostituição da violência sexual, e que a própria prostituição requer consentimento, e que as mulheres que não se prostituem também estão sujeitas a sofrer violências sexuais. E, ao mesmo tempo, não é porque elas são prostitutas que sofreram violência e se sensibilizam com as condições de suas colegas que estão imunes a reprodução de expressões do racismo e da homofobia. E que independente das condições de classe as quais estão inseridas, elas também desejam reproduzir outros estereótipos. Há um diálogo que ilustra esta quebra de expectativa romântica com relação às personagens: "Quero um marido rico, insultar o chofer e bater na empregada". Não são heroínas e nem são vítimas, são pessoas, com trajetórias e sentimentos que fizeram delas o que elas precisam ser para existir. Se o Moudawana representa o código moral que regula as relações das mulheres no conjunto da família, Ayouch nos mostra que a própria a prostituição dispõe também de um código moral próprio.

As discussões apresentadas por Adriana Piscitelli e Angeles Ramírez apontam conclusões similares quando escrevem sobre a necessidade de qualificar os contextos específicos para compreender heterogeneidade das demandas das diferentes mulheres, suas experiências, perspectivas e anseios de forma que se contemple a multiplicidade de experiências. Piscitelli (2012) recorda ainda de processos de invisibilização e silenciamento das demandas das prostitutas na militância brasileira. E me parece ser exatamente essa a contribuição de "Muito Amadas", o rompimento dos estereótipos, fruto de vasta pesquisa realizada sobre a diversidade presente no campo da prostituição marroquina, que insere a autonomia como parte constitutiva daquela narrativa e contribui para dar voz e tornar visíveis as vidas destas mulheres. 


\section{resenha de filme}

\section{Referências bibliográficas}

Abu-Lughod, L. (2013). Do muslim women need saving? Cambridge, Massachusetts;London, England. : Harvard University Press.

Afilial, R. (2008). Do Moudawana ao Código da Família: processos e conteúdos de uma reforma estratégica. Cadernos Pagu (30) , 121-135.

Bedmar, V. L. (2012). O Islã e o sistema escolar no Marrocos pré-colonial. Afro Ásia (45), 123-141.

Benlabbah, F. (2008). Islam y derechos de la mujer en Marruecos. Cadernos Pagu (30), pp. 95-106.

Daich, D. (2012). Prostitución, trata y abolicionismo: conversaciones con Dolores Juliano y Adriana Piscitelli. Revista Avá, Missiones, Argentina: Dossier Ecologia Humana $n^{\circ} 20$, 97 110.

Debert, G. G., \& Gregori, M. F. (2008). Violência e gênero: novas propostas, velhos dilemas. Revista Brasileira de Ciências Sociais volume 23 n66, 165-185.

Ennaji, M. (2008). Pregadoras murshidat como agentes de mudança no Marrocos: : uma perspectiva comparada. Cadernos Pagu (30)d, 75-94.

Fernandez, A. R. (2004). ¿Oriente es Oriente? Feminismo e islamismo en Marruecos. Revista Internacional de Sociología (RIS) ${ }^{\circ}$ 39, pp. 9-33.

França, M. (2017). A vida pessoal de trabalhadoras do sexo: dilemas de mulheres de classes populares. Revista Latinoamericana. Sexualidad, Salud y Sociedad n²5, 134-155.

. (2017). Práticas e Sentidos da aprendizagem na prostituição. Horizontes Antropológicos ano $23 n^{\circ} 47,325-349$.

Harrak, F. (2008). A Salafiyamarroquina e a questão feminina: eitura de l'Autocritiquede Allal el-Fassi. Cadernos Pagu (30), 53-74.

Mahmood, S. (2006). Teoria Feminista, agência e sujeito liberatório: algumas reflexões sobre o revivalismo islâmico no Egito. Etnográfica Volume X (1), pp. 121-158.

Mohanty, C. T. (1984). Under Western Eyes: Feminist Scholarship and Colonial Discourses. boundary 2, Vol. 12, No. 3, pp. 333-358.

Piscitelli, A. (2012). Feminismos e prostituição no Brasil: Uma leitura a partir da antropologia feminista. Cuardenos de Antropología Social $n^{\circ} 36,11-31$.

(2014). Violências e afetos: intercâmbios sexuais e conômicos na (recente) produção antropológica realizada no Brasil. Revista Cadernos Pagu. Dossiê: Antropologia, gênero e sexualidade no Brasil: Balanço e perspectivas, 159-199. 


\section{resenha de filme}

(2016). Economias sexuais, amor e tráfico de pessoas - novas questões conceituais. Cadernos Pagu (47).

Ramírez, Á. (2006). Other feminisms? Muslim associtations and women's participation in Morocco. Revista Etnográfica. Volume X (1), 107-119.

Sadiqi, F. (2008). Estereótipos e mulheres na cultura marroquina. Cadernos Pagu (30), 1132.

Silva, M. C. (2008). As mulheres, os outros e as mulheres dos outros: feminismo, academia e islão. Cardenos Pagu (30), 137-159.

Slenes, R. (2014). Negociação de Sentidos: Violência e Direitos da Mulher na Prática de ONGs em Marrocos. Dissertação de Mestrado defendida no Programa de Pós-Graduação em Antropologia Social. Campinas, São Paulo, Brasil: Portal de dissertações e teses UNICAMP.

Triviño, D. (2014). El concepto occidental de la prostitución en África. Revista Memória Social 18(37), Bogotá, Colômbia. , 52-59. 